\title{
Maternal Biological Grandparent
}

National Cancer Institute

\section{Source}

National Cancer Institute. Maternal Biological Grandparent. NCI Thesaurus. Code

C111248.

A relative who is the biological parent of the biological mother. 